American Journal of Animal and Veterinary Sciences 3 (1): 13-17, 2008

ISSN 1557-4555

(C) 2008 Science Publications

\title{
Physiological Response and Postmolt Performance of Laying Hens Molted by Non-Feed Removal Methods
}

\author{
Fariborz Khajali, Saied Karimi and M.R. Akhari \\ Department of Animal Science, Shahrekord University, Postal Code 88186-34141, Shahrekord Iran,
}

\begin{abstract}
One experiment was conducted to evaluate the physiological response and postmolt performance of laying hens subjected to non-feed removal molting programs. One hundred and eighty 78-week-old Hy-line W36 laying hens were distributed among 45 groups of four birds and located in cages so that mean body weight of each cage was very similar. Three adjacent cages were considered as a replicate and 3 such replicates were assigned to each treatment. There were five treatments (molting procedures): Treatment 1 was continuous feed removal (CFR) and considered as the control. Hens on treatment $2\left(\mathrm{~T}_{2}\right)$ fed ground corn as sole feed ingredient and dietary vitamin and macro and microelement levels were maintained as Hy-line W36 guideline specifications. Treatment 3 was similar to $\mathrm{T}_{2}$ except that salt was removed from diet. Treatment 4 was similar to $\mathrm{T}_{2}$ except that corn was replaced with wheat. Treatment 5 was similar to treatment 4 except that salt was removed from diet. Birds on $\mathrm{T}_{2}$ to $\mathrm{T}_{5}$ were fed at the rate of $50 \mathrm{~g}$ day $^{-1}$. The results indicated that hens subjected to CFR went out of production by Day 5 while those on corn or wheat diets with or without salt ceased egg production from Day 7 to Day 13. Nevertheless, postmolt egg production did not significantly differed among the treatments. Body weight loss in feed-deprived hens during molt was significantly $(\mathrm{p}<0.05)$ greater than non-feed removal treatments when measured on Day 7 and Day 12. Starvation during continuous feed removal resulted in increased heterophil to lymphocyte $(\mathrm{H} / \mathrm{L})$ ratio $(\mathrm{p}<0.05)$, hematocrit and plasma $\mathrm{T}_{4}$ whereas decreased plasma T3 level $(\mathrm{p}<0.05)$.
\end{abstract}

Key words: Feed deprivation; laying hens; molting; non-feed removal

\section{INTRODUCTION}

Molting in avian species is defined as periodic shedding and replacement of feathers which is accompanied by involution of reproductive organs ${ }^{[1]}$. Natural molting of laying hens generally takes four months ${ }^{[12]}$, which raises economic concerns as the hens continue to be fed during non-production times ${ }^{[11]}$. The molting process can be sped up by management practice called induced molting. Induced molting uniformly rests all hens and returns them to a more consistent high rate of lay for an extended period ${ }^{[11]}$. Conventional induced molting program usually involves a period of fasting for 10 to 15 days or up to $30 \%$ body weight reduction achieved ${ }^{[15]}$. Hens subjected to continuous fasting experience stress and are highly susceptible to infection by salmonella ${ }^{[5]}$. Egg industry, therefore, should seek for alternative molting programs to be replaced for continuous feed removal.

Several non-feed removal procedures were used to induce molting in hens. Feeding a high zinc diet was successfully used by Park et al. ${ }^{[13]}$ Use of high fiber diets provided by alfalfa ${ }^{[10]}$ or whole cottonseed ${ }^{[3]}$ was reported to be as effective as complete feed removal program. Koelkebeck et al. ${ }^{[9]}$ have studied the effectiveness of a corn or a wheat diet fed at free access for induction of molt and indicated that layer performance was inferior to feed removal procedure. In present study, feeding a corn or a wheat diet was limited at a rate of $50 \mathrm{~g} \mathrm{day}^{-1}$ either in presence or omitting salt and physiological responses as well as postmolt performance were examined.

\section{MATERIALS AND METHODS}

One hundred and eighty 78-week old Hy-line W36 laying hens were kept in a house equipped with cages $(45 \times 50 \mathrm{~cm})$ and exposed to $16 \mathrm{~h}$ daily photoperiod. Prior to beginning the experiment, all hens were weighted and distributed among 45 cages so that 4 hens were allotted to each cage with equal mean body weight in each cage. Three adjacent cages were considered as a replicate and 3 such replicates were assigned to each treatment. There were five treatments (molting

Corresponding Author: Fariborz Khajali, Department of Animal Science, Shahrekord University, Postal Code 88186-34141, Shahrekord Iran Tel: +98 3814424401 
procedures): Treatment 1 was continuous feed removal (CFR) and considered as the control. Hens on treatment $2\left(\mathrm{~T}_{2}\right)$ fed ground corn as sole feed ingredient and dietary vitamin and macro and microelement levels were maintained as Hy-line W36 guideline specifications. Treatment 3 was similar to $\mathrm{T}_{2}$ except that salt was removed from diet. Treatment 4 was similar to $\mathrm{T}_{2}$ except that corn was replaced with wheat. Treatment 5 was similar to treatment 4 except that salt was removed from diet. Birds on $\mathrm{T}_{2}$ to $\mathrm{T}_{5}$ were fed at the rate of $50 \mathrm{~g} \mathrm{day}^{-1}$.

The experiment was lasted 16 weeks consisted of a four-week period of molt and 12 weeks postmolt lay period. On Day 1 of molt (the initiation of feed withdrawal), the daily photoperiod was decreased to 8 h. On Day 24 and 30, the photoperiod was increased to 10 and $12 \mathrm{~h}$ respectively, then, increased $30 \mathrm{~min}$ per week until a photoperiod of $16 \mathrm{~h}$ was reached at peak production. Hens were fed ad libitum according to Hyline W36 commercial management guide manual (2005) during postmolt period of 12 weeks.

Records of body weight were kept before induction of molt (Day 1), Day 12 when around 30\% BW reduction occurred and Day 28 which was end of molt period. Blood samples were taken from the brachial vein of one hen per replicate ( 9 hens/treatment) on Day 1(before molt), Day 14 (mid-molt) and Day 28 (end of molt). Blood samples were used for determination of hematocrit and differential leukocyte counts ${ }^{[7]}$. Plasma was discarded by centrifugation at $1400 \mathrm{~g}$ for $15 \mathrm{~min}$ and plasma samples were used to measure $\mathrm{T}_{3}$ and $\mathrm{T}_{4}$ hormone concentrations by radioimmunoassay using a commercial kit (REF KT2CT, Barcelona, Spain). Records of egg production were kept daily for 12 weeks post molts and records of egg weight were kept monthly during aforementioned period.

Data were subjected to a complete randomized block design and analyzed by GLM procedure of SAS software (1997). Duncan multiple range test as well as orthogonal contrasts was used to compare treatment means.

\section{RESULTS AND DISCUSSION}

The reduction in hen-day egg production during a $28 \mathrm{~d}$ molt period is shown in Fig. 1. The figure indicates that hens on continuous feed removal went out of production by Day 5 whereas those on corn or wheat diets either with or without salt ceased egg production from Day 7 to 13.

Orthogonal contrast showed that body weight loss was significantly differed between continuous fasting and other treatments. Table 1 depicts trend of BW loss among the molting methods. Hens of the control lost 24 and $28 \%$ of their initial body weight by Day 7 and 12 , respectively, which was significantly greater than other molting methods. Birds on the control group gained higher than those on non-feed removal groups during refeeding so that they had even higher body weight on Day 28.

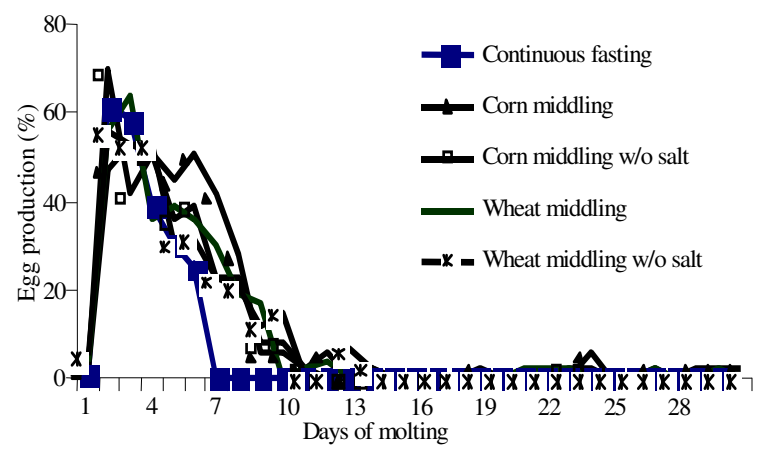

Fig. 1: Regression in egg production during molting period among molting programs

Table 1: Changes in body weight of hens measured at different times during molt period

\begin{tabular}{llll}
\hline & Body weight $(\mathrm{g})$ & & \\
& - & & \\
Molting procedure & Day 7 & Day 12 & Day 28 \\
\hline Continuous feed removal & $1232.2(24.0)^{\mathrm{b}}$ & $1177.0(28.0)^{\mathrm{c}}$ & $1365.6(15.8)^{\mathrm{a}}$ \\
Corn diet & $1491.7(8.0)^{\mathrm{a}}$ & $1450.3(10.6)^{\mathrm{a}}$ & $1324.2(18.4)^{\mathrm{ab}}$ \\
Corn diet without salt & $1467.5(9.6)^{\mathrm{a}}$ & $1406.4(13.3)^{\mathrm{ab}}$ & $1271.9(21.6)^{\mathrm{b}}$ \\
Wheat diet & $1461.9(9.9)^{\mathrm{a}}$ & $1416.1(12.7)^{\mathrm{ab}}$ & $1280.8(21.1)^{\mathrm{b}}$ \\
Wheat diet without salt & $1435.5(11.5)^{\mathrm{a}}$ & $1375.4(15.2)^{\mathrm{b}}$ & $1271.7(21.6)^{\mathrm{b}}$ \\
SEM & 20.95 & 18.35 & 18.32 \\
\hline
\end{tabular}

Means within each column with uncommon superscript have significant difference $(\mathrm{p}<0.05)$. Data in parentheses show body weight loss as a percent of initial body weight 
American J. Animal \& Vet. Sci., 3 (1): 13-17, 2008

Table 2: Thyroid hormone concentrations of hens subjected to different molting programs at different times during molt period

\begin{tabular}{|c|c|c|c|c|c|c|}
\hline \multirow[b]{2}{*}{ Molting procedure } & \multicolumn{3}{|c|}{$\mathrm{T} 3\left(\mathrm{ng} \mathrm{dL}^{-1}\right)$} & \multicolumn{3}{|c|}{$\mathrm{T} 4\left(\mu \mathrm{g} \mathrm{dL}{ }^{-1}\right)$} \\
\hline & Day 7 & Day 14 & Day 28 & Day 7 & Day 14 & Day 28 \\
\hline Continuous feed removal & $290.4 \mathrm{a}$ & 242.5 & 269.4 & 1.50 & 2.14 & 1.53 \\
\hline Corn diet & $285.4 \mathrm{a}$ & 210.9 & 326.2 & 1.58 & 1.83 & 1.60 \\
\hline Corn diet without salt & $251.8 \mathrm{ab}$ & 223.1 & 282.6 & 1.51 & 1.94 & 1.54 \\
\hline Wheat diet & $262.4 \mathrm{ab}$ & 255.8 & 277.4 & 1.86 & 2.17 & 1.54 \\
\hline Wheat diet without salt & $170.9 \mathrm{~b}$ & 304.7 & 288.3 & 1.68 & 2.11 & 1.58 \\
\hline SEM & 27.28 & 41.06 & 19.34 & 0.26 & 0.34 & 0.16 \\
\hline
\end{tabular}

Means within each column with uncommon superscript have significant difference $(\mathrm{p}<0.05)$

Table 3: Hematocrit and heterophil to lymphocyte ratio in hens subjected to different molting programs at different times during molt period

\begin{tabular}{|c|c|c|c|c|c|c|}
\hline \multirow[b]{2}{*}{ Molting procedure } & \multicolumn{3}{|c|}{ Hematocrit } & \multicolumn{3}{|l|}{$\mathrm{H}: \mathrm{L}(\%)$} \\
\hline & Day 7 & Day 14 & Day 28 & Day 7 & Day 14 & Day 28 \\
\hline Continuous feed removal & 40.9 & 39.4 & 38.8 & $0.81 \mathrm{a}$ & 0.79 & $0.86 \mathrm{a}$ \\
\hline Corn diet & 37.7 & 40.4 & 41.9 & $0.48 \mathrm{c}$ & 0.59 & $0.67 \mathrm{ab}$ \\
\hline Corn diet without salt & 36.9 & 40.6 & 42.0 & $0.66 \mathrm{abc}$ & 0.62 & $0.60 \mathrm{bc}$ \\
\hline Wheat diet & 37.4 & 39.3 & 43.9 & $0.72 \mathrm{ab}$ & 0.50 & $0.48 \mathrm{c}$ \\
\hline Wheat diet without salt & 33.9 & 43.9 & 44.3 & $0.61 b c$ & 0.56 & $0.76 a b$ \\
\hline SEM & 1.81 & 1.39 & 1.34 & 0.058 & 0.095 & 0.054 \\
\hline
\end{tabular}

Means within each column with uncommon superscript have significant difference $(\mathrm{p}<0.05)$

Table 4: Postmolt performance of laying hens subjected to different molting programs

\begin{tabular}{lllcc}
\hline Molting procedure & HDEP $(\%)$ Wk 5-17 & Peak egg production $(\%)$ & Mean egg mass wk5-17 $(\mathrm{g} / \mathrm{b})$ & Egg mass at peak $(\mathrm{g} / \mathrm{b})$ \\
\hline Continuous feed removal & 61.3 & $74.8 \mathrm{a}$ & 3966.7 & 5320.0 \\
Corn diet & 57.1 & $62.4 \mathrm{~b}$ & 3787.0 & 4718.0 \\
Corn diet without salt & 59.7 & $69.3 \mathrm{ab}$ & 3976.0 & 5236.0 \\
Wheat diet & 63.0 & $75.0 \mathrm{a}$ & 4081.0 & 5439.0 \\
Wheat diet without salt & 60.7 & $70.2 \mathrm{a}$ & 3894.3 & 5096.0 \\
SEM & 3.27 & 3.45 & 296.5 & 392.4 \\
\hline
\end{tabular}

Means within each column with uncommon superscript have significant difference $(\mathrm{p}<0.05)$

Starvation during molting significantly decreased plasma $\mathrm{T}_{3}$ level with concomitant elevation of plasma $\mathrm{T}_{4}$ level (compare the means on Day 7). Refeeding restored the changes in plasma $T_{3}$ and $T_{4}$ concentrations (compare the means on Day 14 and 28) (Table 2).

Hematocrit value was numerically higher in birds subjected to fasting method compared to non-fasting groups when measured on Day 7 indicating that fasting elevated this variable. Nevertheless, the difference with respect to this variable was not significant (Table 3). The situation was restored during refeeding (compare hematocrit on Day 14 and Day 28).

Feed deprivation during molt significantly $(\mathrm{p}<0.05)$ enhanced $\mathrm{H} / \mathrm{L}$ ratio (Table 3 ). The elevated ratio of $\mathrm{H} / \mathrm{L}$ was maintained significant until the end of molt (Day 28).

Table 4 depicts results pertaining hen-day egg production and egg mass during postmolt period. The highest egg production rate and egg mass at month of peak or during $12 \mathrm{wk}$ period postmolt were attained by hens fed wheat as a sole source of feed ingredient during molt period. Hens on corn diet had significantly $(\mathrm{p}<0.05)$ lower egg production at peak in comparison with other groups. They had the lowest egg production during entire postmolt period.

Birds subjected to continuous fasting ceased egg production much earlier than those on non-feed removal programs. This observation was definitely expected as hens on the control received no nutrient to maintain egg production.

Body weight of hens experienced continuous fasting was much drastically lost when compared to that of hens on non-fed removal programs. After 7 days in molt, hens of the control lost $24 \%$ of their initial body weight whereas BW loss did not exceed $11.5 \%$ in nonfeed removal programs at the same time. Birds on the control group gained higher than those on non-feed removal groups during refeeding so that they had even higher body weight on Day 28. Khajali et al. ${ }^{[8]}$ demonstrated that ovary and oviduct had highest regressions during feed deprivation due to loss of gonadotropin support.

Feed deprivation during molting led to decreased plasma $T_{3}$ concentration and increased plasma $T_{4}$ 
concentration. Refeeding restored normal plasma $T_{3}$ and $\mathrm{T}_{4}$ levels (Table 2). This is consistent with previous reports ${ }^{[4,14]}$. The decrease in plasma $T_{3}$ level in feed deprived hens is likely to be the result of a shift in the balance between deiodination of $\mathrm{T}_{4}$ by hepatic deiodinase enzyme type $\mathrm{I}$ (D1) and $\mathrm{T}_{3}$ degradation by hepatic deiodinase enzyme Type III (D3) [4] Decuypere et al. ${ }^{[4]}$ reported increased hepatic deiodinase III mRNA levels at the first day of starvation which was dropped after refeeding.

Starvation during molting resulted in elevated hematocrit and refeeding caused it to return to the level similar to that of before molting. There are reports suggesting that starvation during molting increases packed cell volume ${ }^{[6]}$. Molting causes a remarkable regression in ovary and oviduct weight ${ }^{[8]}$ which is associated with the loss of estrogenic activity. According to Keshavarz and Quimby ${ }^{[6]}$, the loss of estrogenic activity could result is increased erythropoiesis and accounts for enhanced hematocrit.

Heterophil to Lymphocyte ratio is commonly used as an indicator of stress ${ }^{[16]}$. Under stress conditions the ratio is tended to increase ${ }^{[2]}$. Davis et al. ${ }^{[2]}$ showed that $\mathrm{H} / \mathrm{L}$ ratio was significantly higher during a forced molt compared to other times of year. As depicted in Table 3, fasting resulted in higher rate of $\mathrm{H} / \mathrm{L}$ (compare the treatments on Day 7) and elevated ratio of $\mathrm{H} / \mathrm{L}$ was maintained significant until the end of molt (Day 28). This finding shows that fasting during molting is a vigorous stress to the birds and emphasizes seeking for alternative molting practices for this conventional procedure.

Postmolt egg production and egg mass were of important results. The highest egg production rate and egg mass at month of peak or during $12 \mathrm{wk}$ period of postmolt were attained by hens fed wheat as a sole source of feed ingredient during molt period. In the other hand, hens fed corn diet had the lowest egg production at peak and entire postmolt period. Wheat has higher amount of crude protein and better balance of amino acids relative to corn. Consequently, feeding corn might have depleted body protein reserves and resulted in decreased egg production in postmolt.

\section{CONCLUSIONS}

Feed deprivation during molting is associated with increased plasma $T_{4}, H / L$ ratio, and hematocrit, while plasma $T_{3}$ is reduced. The findings of the present study indicates that feeding a wheat diet at limited amount can be resulted in postmolt performance comparable to the continuous feed deprivation with beneficial effects to alleviating the stress as measured through decreased $\mathrm{H} / \mathrm{L}$ ratio.

\section{ACKNOWLEDGEMENT}

This research was funded by Shahekord University. Authors wish to express their appreciation to the university.

\section{REFERENCES}

1. Berry, W.D., 2003. The physiology of induced molting. Poult. Sci., 82: 971-980.

2. Davis, G.S., K.E., Anderson and A.S. Carroll, 2000. The effect of long-term caging and molt of Single White Leghorn hens on heterophil to lymphocyte ratios, corticostrone, and thyroid hormones. Poult. Sci., 79: 514-518.

3. Davis, A.J., M.M. Lordelo, and N. Dale, 2002. Use of cottonseed meats in molting programs. J. Applied Poult. Res., 11: 175-178.

4. Decuypere, E., P. Van As, S.G. Van der and V.M. Darras, 2005. Thyroid hormone availability and activity in avian species: A review. Domestic Anim. Endocrinol., 29: 63-77.

5. Holt, P.S., 2003. Molting and Salmonella enterica serovar enteritidis infection: The problem and some solutions. Poult. Sci., 82: 1008-1010.

6. Keshavarz, K. and F.W. Quimby, 2002. An investigation of different molting techniques with an emphasis on animal welfare. J. Applied Poult. Res., 11: 54-67.

7. Khajali, F., E.A. Khoshouie and A.K.Z. Moghaddam, 2006. Effect of vitamin and trace mineral withdrawal from finisher diets on growth performance and immunocompetence of broiler chickens. Br. Poult. Sci., 47: 159-162.

8. Khajali, F., E. A. Khoshouie and F. Rafiei, 2007. Application of short fasting methods to induce molting in commercial laying hens. Proceedings of 16th European Poultry Nutrition Conference, Strasbourg, France.

9. Koelkebeck, K.W., P.W. Parsons, P. Biggs and P. Utterback, 2006. Nonwithdrawal molting programs. J. Applied Poult. Res., 15: 483-491. 
10. Landers, K.L., C.L. Woodward, X. Li, F. Kubena, D.J. Nisbet and S.C. Ricke, 2005b. Alfalfa as a single source for molt induction in laying hens. Bioresour. Technol., 96: 556-570.

11. McDaniel, B.A. and D.R. Aske, 2000. Egg prices, feed costs and the decision to molt. Poult. Sci., 79: 1243-1245.

12. North, M.O. and D.D. Bell, 1990. Commercial Chicken Production Management. 4th Edn. Chapman and Hall, New York.

13. Park, S. Y., S. G. Birkhold, L. F. Kubena, D.J. Nisbet, and S. C. Ricke, 2004. Effects of High Zinc Diets Using Zinc Propionate on Molt Induction, Organs, and Postmolt Egg Production and Quality in Laying Hens. Poult. Sci. 83: 24-33.
14. Reyns, G.E., K.A. Janssens, J. Buyse, E.R. Kuhn and V.M. Darras, 2002. Changes in thyroid hormone levels in chicken liver during fasting and refeeding. Comp. Biochem. Physiol. Part B, 132: 239-245.

15. Ruszler, P.L., 1998. Health and husbandry considerations of induced molting. Poult. Sci., 77: 1789-1793.

16. Vleck, C.M., 2001. Comparison of corticosterone and heterophil to lymphocyte ratios as indicators of stress in free-living birds. In: Avian Endocrinology (Dawson, A. and C.M. Chaturvedi, Eds.). Narosa Publishing, New Delhi, pp: 401-411. 